\title{
guaraqueçaba, 0 COMANDANTE SLOCUM E A PROEZA DO BARCO "LIBERDADE"
}

\author{
Newton Carneiro
}

Nos últimos anos do Império já pouco restava dos afa mados estaleiros do litoral paranaense, que chegaram a construir unidades até para a nossa marinha de guerra como foi o caso do brigue "D. Pedro II".

Vieira dos Santos, Ermelino de Leão, Francisco Negrão relacionam embarcações, seus nomes, características, tonelagens e outros detalhes dos veleiros, mais afamados, feitos em $\mathrm{Pa}$ ranaguá e Antonina.

A crônica não menciona, porém, inicativas semelhantes em Guaraouecaba; e foi desse remoto porto que saiu o mais famoso barco já construico no Paraná.

Em plena baía dos Pinheiros estava ancorado o grande veleiro "Aquidneck", elegante barco de três mastros e 365 toneladas, construido em Connecticut e arvorando pavilhão norte americano.

Seu comandante era o capitão Joshua Slocum, que conhecia a Provincia do Paraná e seus portos, de outras passagens em que carregara erva-mate para Montevideo.

Indisposto com as dificuldades que enfrentara na Argentina, pensava voltar ao comércio e transporte de madeira. Fora-lhe rendoso o negócio no Oriente, quancio vendia na China taboado adquirido nas Filipinas. Ia tentar a venda de madeiras do Paraná nos Estados Unidos. Para isso era-line indispensável um barquinho auxiliar para a compra dos toros nas reentrancias costeiras de dificil acesso. 
Mas a sorte nāo bafejava o "Arquidneck" nesse roteiro, em que trazia a bordo a familia do comandante.

Desfazendo-se dos surrões de mate que tomara em Antonina, o barco americano ruma para o Prata e sobe o rio Paraná para carregar alfafa no porto de Rosário. Na ocasião grassava na Argentina serissima epidemia de colera. Dirige-se para o Rio de Janeiro, porto de destino da carga que levava. advertido, porém, de que deveria submeter-se aos rigores de uma quarentena na Ilha Grande.

A supervisão do confinamento naval na ilha-lazareto estava a cargo do Almirante Custódio José de Melo, de bordo do cruzador "Aquidaban", celebrizado poucos anos depois pelos acontecimentos de 1894 .

Não obstante as insistentes representaçōes do capitão Slocum, não lhe foi permitido fazer a quarentena com o "Aquidneck", e o veleiro teve que retornar a Rosario para descarregar a alfafa, com prejuizos facilmente imagináveis...

Jamais esqueceu a aparente discriminação e o tratamento que lhe dispensou o comandante brasileiro, de quem pensou tirar desforra mais tarde ao aceitar comissionamento para comandar navio da "esquadra de papel", que Florino Peixoto comprou nos Estados Unidos para enfrentar a revolta de Custódio de Mello.

Retornando com o seu grande veleiro a Paranaguá, o capitão Slocum decidiu carregar madeira, por sua conta, e navegou barra a dentro. Mas como o "tender" do "Aquidneck" não oferecia condiçōes satisfatórias para o trabalho de aquisiçāo de taboas, vigas e toros, decidiu construir novo barquinho auxiliar.

O melhor empreiteiro que encontrou foi um jovem e ativo carpinteiro de Guaraqueçaba (cujo nome infelizmente não registrou). Decidida a tarefa e feito o piovimento de recursos para a aquisição do material e engrajamento de auxiliares, inesperado acidente altera todos os planos.

O belo e magestoso "Aquidneck", desviado por forte vento do mar encalha irremediávelmente nos baixios da baía dos Pinheiros. A presença do barco americano e seu infortunio causaram, como é fácil imaginar-se, enorme impacto entre o povo daqueles êrmos do nosso litoral. Guilherme Michaud, o pintor-patriarca do Superagui dedica-lhe vários desenhos, dois 


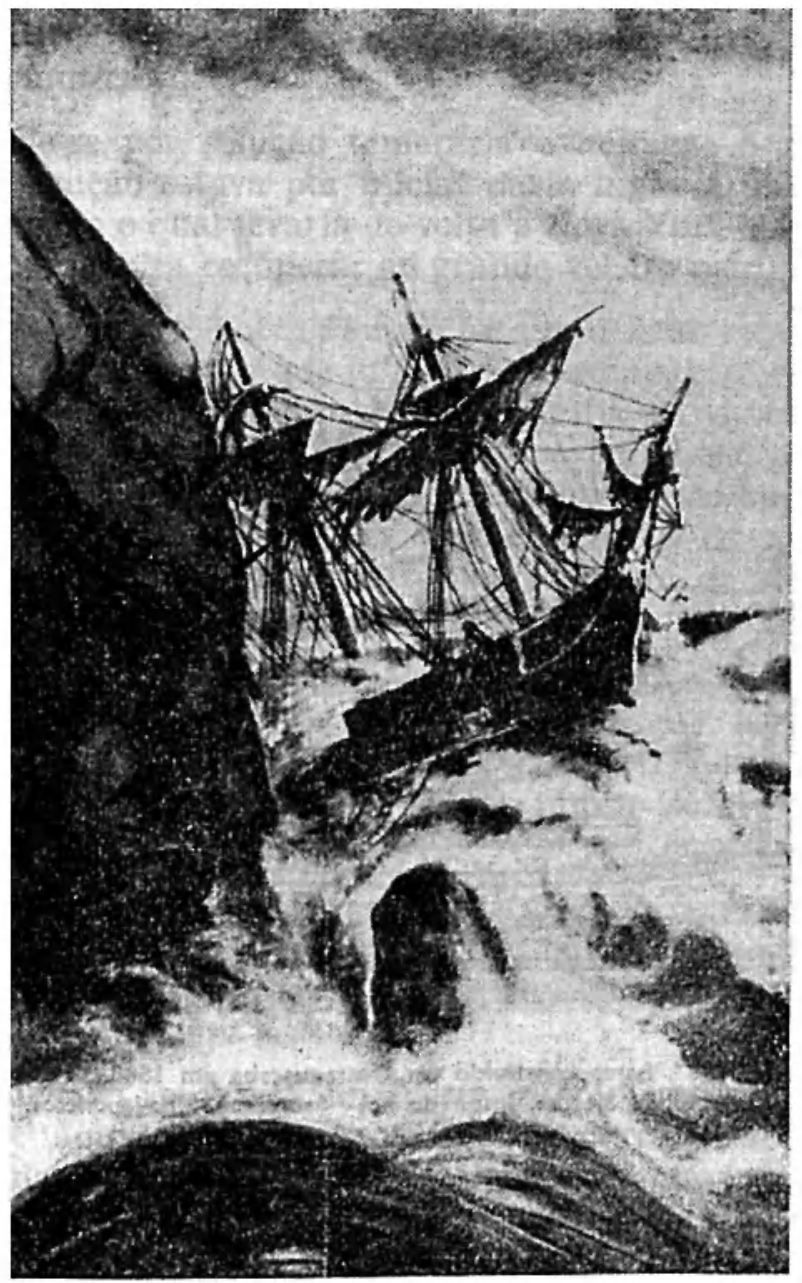

Destroços de "Aquidneck", o veleiro do Capitão Joshua Slocum, que se perdeu na baía de Paranaguá, segundo aquaiela de Guilherme Michaud. 


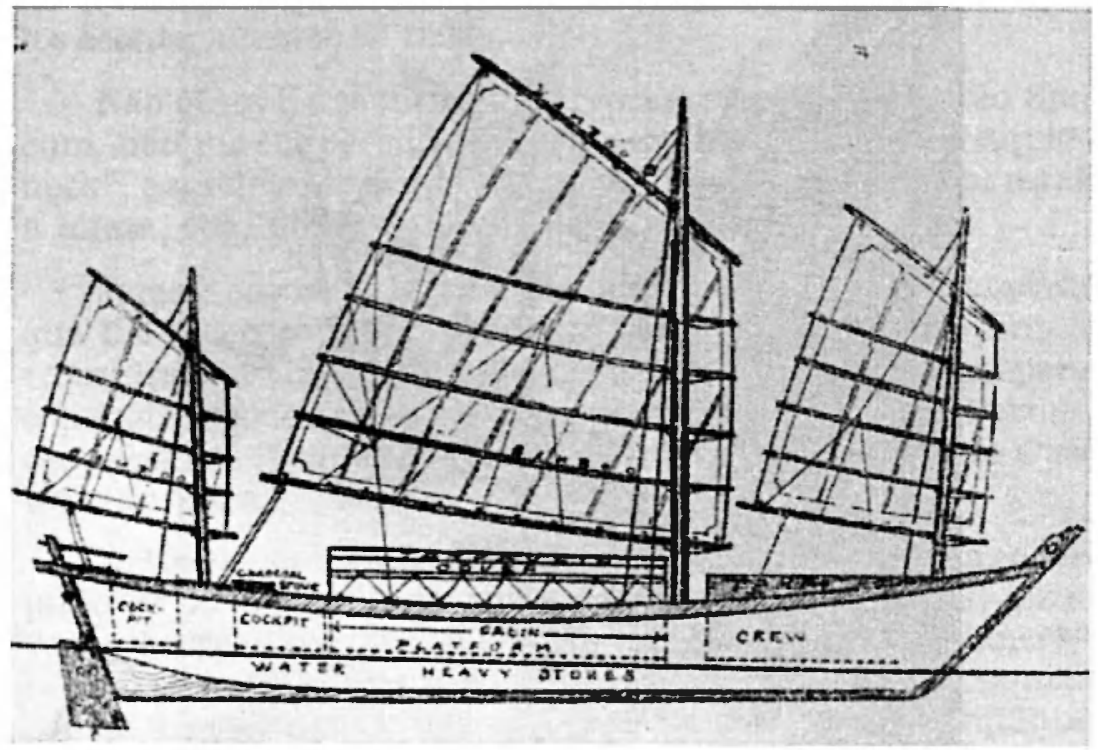

Projeto do "Liberdade", barco construido em Guaraqueçaba em 1888. O desenho é do próprio Capitão Slocum, inspirada nos "Sampans", sino-japoneses. 
dos quais envia ao seu amigo ex-Presidente da Província, Visconde de Taunay. Um deles mostra o barco ancorado na baía, rodeado de pequenas embarcações. Outro já o pinta semi-destruido contra os rochedos de alguma ilhota do fundo da baia.

Baldados os esforços para livrar seu barco, Slocum defronta-se com o problema de repatriar a esposa e dois filhos assim como salvar e transportar bagagens, pertences e instrumentos carinhosamente guardados desde o início de sua carreira náutica.

Decide-se por solução temerária e heróica: o "tender", cuja construção estava por iniciar daria lugar a um iate de alto mar, com o qual levaria de volta a Nova York sua familia e o que conseguira recuperar ao grande veleiro perdido.

Para projetar o barco Slocum faz uso de suas experiências asiáticas, do tempo em que integrava as equipagens dos "China Clippers". Como dispunha da fotografia de vistoso "sampan" japonês, o desenho resultou numa embarcação de tipo oriental, sobretudo em função dos flutuadores de bambu que lhe adicionou e que tanto lhe valeram contra os vagalhões. Deu-lhe 35 pés de comprimento, com largura de sete pés e meio na pôpa e peso de seis toneladas.

A quilha foi construida de cedro e a parte do fundo ce "páu ferro". Para obter as ferragens necessárias, inclusive os pregos de latão, Slocum vasculhou todos os ferreiros e carroceiros de Paranaguá. Faltando rebites, improvisıu-os com vintens de cobre...

O peso excepcional das pranchas de "páu ferro" (com espessura de uma polegada e um quarto) em contraste com a leveza do cédro, deu ao barco notável estabilidade ainda realçada pelos flutuadores laterais.

O que não se obteve em Paranaguá foi retirado da carcassa do "Aquidneck", cuja oficina de carpintaria foi toda transferida para o improvisado estaleiro de Guaraqueçaba, onde o capitão e sua familia se hospedaram durante os longos e trabalhosos meses da construção.

A 13 de maio de 1888, completada a quilha, foi o barco lançado às águas da nossa baía com o nome de "Liberdade", em homenagem à Lei Aurea que acabava de ser promulgada pela Princesa Izabel.

Os Slocum, originários do leste setentrional, traziam so- 
lida formação anti-escravagista. Na Guerra de Sucessão, Henry Warner Slocum, participou de toda a campanha da Virginia batendo-se, inclusive, na batalha de Gettysburg, já promovido a general e comandante de Corpo de Exército.

Ao tempo da sua estada em Guaqueçaba, Joshua tinha 44 anos e estava casado pela segunda vez. Dotado de variada e ativa experiência em todos os mares do mundo, aliás como os seus antepassados, era republicano e admirador de Lincoln.

O acabamento final do "Libcrdade" ainda levou dias, pois cabine, coberta e outros detalhes exigiam trabalho paciente e cuidadoso. Como toda a família contribuiu com mão de obra, o barco não custou mais de cem dolares.

Depois de testado nas águas da baía, decidiu-se que o iate estava pronto e a 24 de junho partiu barra fora com todas as velas cheias.

Conseguir-lhe a documentação indispensável foi tarefa dificil que Slocum contornou obtendo licença simulada para pesca em alto mar. Já a esse tempo se "quebrava o galho"...

No Rio o documento foi substituido por papel regular e correto obtido no Ministério da Marinha, graças a uma recomendação do Marquês de Tamandaré.

A noticia da projetada aventura do "Liberdade" causou sensação na Capital do Império. Os jornais dela se ocuparam e o próprio Ministro da Marinha, Visconde Vieira da Silva, interessou-se pelo destemido navegador.

"O Paiz" diz ter confiança "na perícia e sangue frio do audacioso marinheiro americano", por isso "esperava dentro em pouco tempo vêr o scu nome proclamado por todos os joi"nais do velho e do novo mundo".

Conhecendo a origem do pequeno barco, tanto "O Paiz" como os demais jornais reclamam para o Brasil uma parte da gloria.

A 23 de julho de 1888 o "Liberdade" deixa o Rio de Janeiro no rumo de Cabo Frio, onde uma baleia de vinte metros de comprimento quase põe fim à viagem de Joshua Slocum e sua familia.

Reparados os estragos prossegue o iate para Caravelas, São 
Paulo (na ilha de Tinharé), Salvador, Recife, Barbados, Mayaguez (Porto Rico), Cabo Romano (Carolina do Sul), até alcançar Washington pelo rio Potomac, a 27 de dezembro.

De Guaraqueçaba à costa norte-americana o pequeno veleiro cobriu 5.510 milhas, em 53 dias de navegação!

Enfrentou as temidas tormentas tropicais da costa baiana; tempestades e vendavais no mar das Antilhas; agigantando cetáceo que por pouco o destrói em Cabo Frío; atravessa baixíos e escolhos, a tudo resistindo a flexibilidade e o vigor das madeiras paranaenses postas a serviço da tempera e da sabedoría do rijo lobo do mar norte-americano!

Homenagens especiais mereceram a esposa e os dois meninos-marinheiros, que deram sobejas provas de valor nesSes dois meses de odisséia. Henrietta cosinhava, lavava roupa, remendava o velame. Vitor, já adolescente, era o braço direito do pai, como confirmado grumete; e o pequeno Garfield, fazia de tudo, até turno de vigía!...

Depois do reencontro com amigos e parentes, teve Slocum que satisfazer a curiosidade da imprensa e atender o insistente interêsse público. O "Liberdade" foi entregue à Smithsonian Institution, onde esteve exposto por muitos anos e foi admirado por milhões na capital dos Estados Unidos.

O renome do comandante Joshua Slocum alcançaria, poucos anos depois, todos os quadrantes do mundo, como antevira "O Paiz"; pois com o pequeno veleiro "Spray", faria a volta ao mundo, em 1906, portanto vinte anos antes da proeza solitária que celebrezou Alain Gelbault. Esse exito deveu-o, como o próprio marujo o reconhece, à sua experiência anterior no "Liberdade".

Seus feitos repercutem até hoje graças ao livro de seu filho e companheiro Vitor, "A Vida e os Feitos do Comandante Joshua Slocum", publicado ao mesmo tempo em Nova York e Toronto (1950), seguindo-se edição inglesa em 1952.

Nele a mais singela e expressiva homenagem ao Brasil é a inserção do diálogo entre o comandante do "Liberdade" e 0 rude camponês que o abriga ao pisar solo norte-americano.

"Os brasileiros libertaram os escravos e não tiveram guer- 
rà", declara-lhe Slocum, como para justificar o nome da sua embarcação.

"Muito bem, muito bem digo-lhe eu" responde Anderson. E conclui pensativo e pragmático:

"Sabe que os sulistas foram tolos? Tiveram guerra, e acabaram também tendo que libertar os pretos..." 


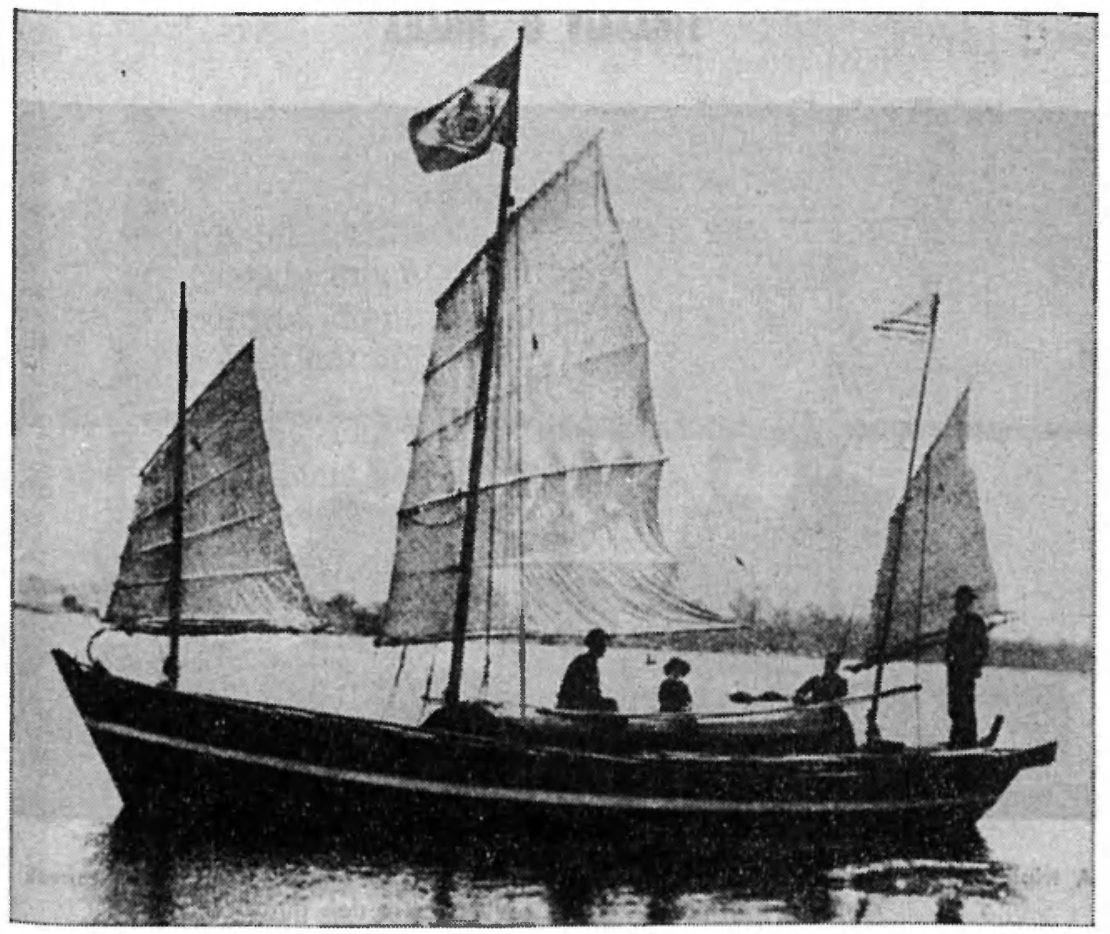

O "Liberdade", arvorando o pavilhāo imperial do Brasil, chega triunfalmente a Calpe Fear River, na Carolina do Norte. 


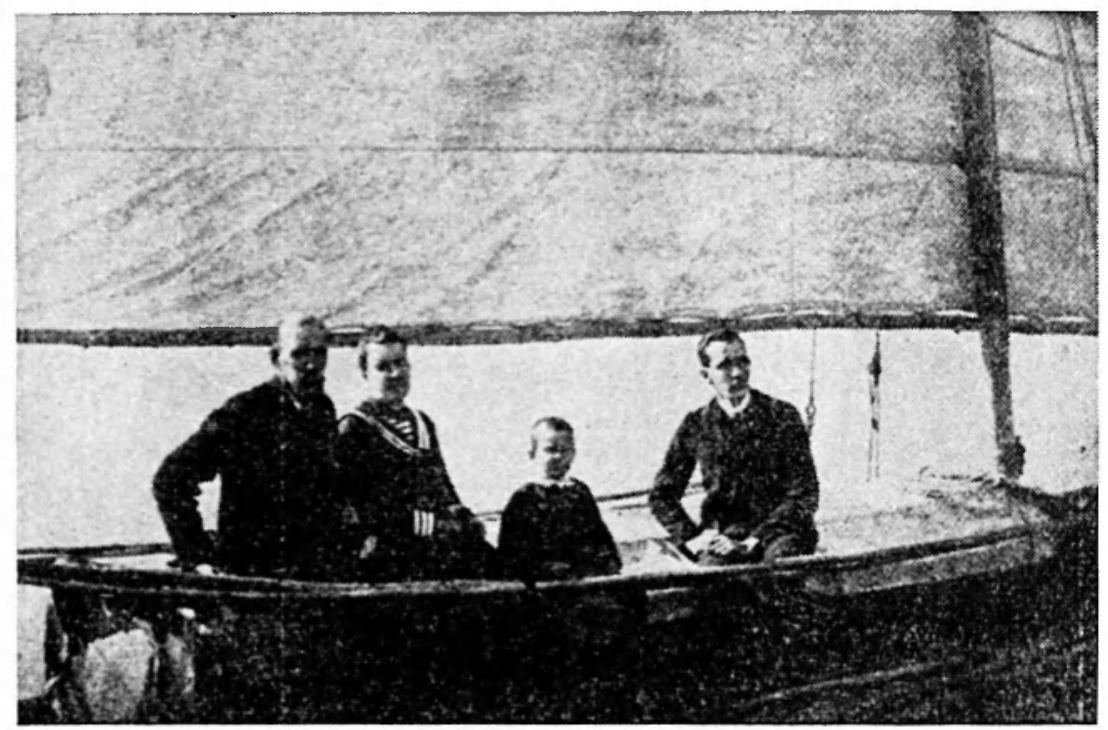

A tripulaçăo do "Liberdade". Da esquerda para a direita o capităo Slocum, sua esposa Henrieta, o pequeno Garfield e Victor, seus dois filhos. 